\title{
Estructura semántica y estructura conceptual en la conformación del sentido pragmático*
}

\author{
The semantic and conceptual structure of \\ dynamic pragmatic meaning
}

RICARDO MALDONADO

Centro de Lingüística Hispánica

Instituto de Investigaciones Filológicas

Universidad Nacional Autónoma de México

Circuito Mario de la Cueva s/n

Ciudad Universitaria, UNAM

México 04510

msoto@unam.mx

Resumen: El presente estudio se encarga de analizar el modo en que la conformación semántica de las formas léxicas determinan los sentidos pragmáticos que emergen en el discurso. La propuesta se ejemplifica con el estudio de dos formas con configuración sintáctica radicalmente distinta: el adjetivo claro y la preposición-conector según. El análisis intenta demostrar que el comportamiento pragmático de ambas formas está determinado y es restringido por la representación esquemática de la forma de base. Siguiendo a Langacker $(1985,1990)$, se propone un proceso de subjetivización en que la pérdida de rasgos semánticos (atenuación semántica) involucra una participación incremental del conceptualizador en la configuración de distintos tipos de sentido pragmático.

Palabras clave: Subjetivización. Marcadores pragmáticos. Conectores. Marcadores del discurso. Pragmaticalización. Según. Claro.
RECIBIDO: 26 DE JUNIO DE 2016 ACEPTADO: 14 DE MARZO DE 2017

\begin{abstract}
This paper attempts to analyse the way in which the semantic configuration of a lexical form determines the pragmatic senses developed in discourse. Two radically different syntactic forms are used for analysis, the adjective claro and the preposition-connector según. The analysis shows that the pragmatic behaviour of these unrelated forms is determined and restricted by the schematic semantic representation of the base form. Following Langacker $(1985,1990)$, it is proposed that a process of subjectification via semantic bleaching involves an increasing loss of semantic features, which in turn involves an equally increasing degree of participation of the conceptualizer in the constitution of different types of pragmatic senses.
\end{abstract}

Keywords: Subjectivity. Pragmatic markers. Discourse markers. Connectors. Pragmaticalization. Según. Claro.

* El presente estudio fue realizado con el apoyo del Programa de Apoyos para la Superación del Personal Académico (PASPA) de la Dirección General de Asuntos del Personal Académico de la Universidad Nacional Autónoma de México. 


\section{INTRODUCCIÓN}

$\mathrm{D}$ ado el grado de avance de las investigaciones sobre los marcadores de discurso, hay poco espacio para dudar que el significado que aportan tales marcadores es de corte pragmático. Tampoco hay mayor desacuerdo en reconocer que son extra oracionales, que su sentido pragmático no contribuye a las condiciones de verdad de la proposición, que tienen independencia sintáctica y que tienen un contorno entonacional propio (Briz; Martín Zorraquino y Portolés).

También parece incuestionable que la conformación del sentido pragmático de los marcadores de discurso implique un importante proceso de subjetivización según el cual el evento es presentado en conformidad con la mirada del conceptualizador. La manera en que se da dicho proceso, en cambio, ha sido tema de notables discusiones. Todo parece indicar que el debate se puede reducir a dos tendencias fundamentales. Por una parte, el significado obedece a procesos inferenciales de corte pragmático; por otra, se da un proceso de atenuación semántica en que la pérdida de distintos rasgos semánticos dispara la emergencia de la mirada subjetiva del conceptualizador. Esta última mirada es la que sostiene Langacker $(1985,1990)$ desde la perspectiva de la gramática cognitiva, una teoría que sostiene la hipótesis de que hay una íntima relación entre procesos cognitivos y lingüísticos y que tales procesos permean el comportamiento del lenguaje desde lo fonémico hasta lo pragmático. En ese sentido, la sintaxis, la semántica y la pragmática forman un continuo que presenta importantes interconexiones y cuya separación obedece más a las necesidades de teorías específicas que a la organización simbólica de la lengua. El autor propone que en la subjetivización interviene un importante proceso de atenuación semántica en que la forma léxica atenúa su configuración al perder rasgos semánticos y ello implica una incremental participación por parte del conceptualizador. La desemantización implica, pues, procesos importantes de subjetivización. Langacker muestra este proceso por medio de la gramaticalización del verbo go que ilustro aquí con su equivalente español $i r$ :

1. Adrián va a la escuela

2. Adrián va a tocar la guitarra

3. Adrián va ser guitarrista

4. Te voy a [buá] dar una patada

5. Va a hacer calor [locativo]

[locativo / intencional]

[(futuro) predictivo]

[(futuro) potencial]

[futuro] 
Del significado locativo de (1), en que el sujeto recorre una trayectoria, se desprenden otros que pierden rasgos del núcleo sémico para incorporar valores en los que participa el conceptualizador. En (2), ir se orienta a una representación abstracta en que no está claro si la trayectoria es física o intencional. La pérdida de los rasgos físicos licencia la emergencia de un significado predictivo, como en (3). Es predictivo puesto que las actividades de Adrián sugieren que llegará a ese fin. La solidez de la predicción disminuye cuando no se cuenta con suficientes datos para aseverar nada. De ahí que el significado sea ahora solo potencial, como en (4). Nótese la reducción fonológica de lo que ya es prácticamente un nuevo verbo [buá]. El último paso lo constituye la gramaticalización de ir como marcador de futuro. En (5), la ocurrencia del evento en un tiempo posterior se proyecta hacia el futuro, ya como marcador temporal, de manera que ni la predicción ni la potencialidad sean identificables. El proceso puede ser esquematizado en términos de la cadena progresiva expuesta en (6):

6. trayectoria $>$ abstracción de trayectoria $>$ disminución potencial subjetiva $>$ marcación de futuro

La trayectoria de ir se transforma en la trayectoria mental que sigue el hablante y ella va tomando cargas subjetivas que al final se pierden en favor de una representación esquemática temporal. En cada paso se pierde por lo menos un rasgo semántico que el hablante recupera de manera subjetiva. Ese proceso de subjetivización lo representa Langacker en las Figuras 1 a 3:

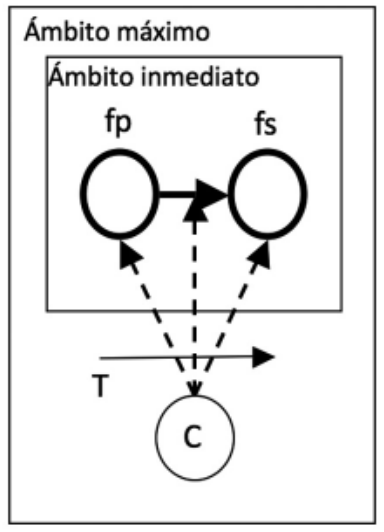

Figura 1.

Configuración inicial

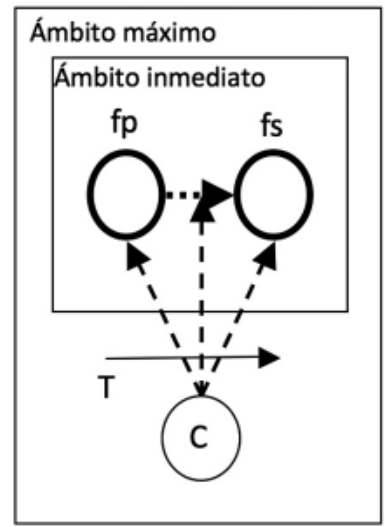

Figura 2.

Atenuación

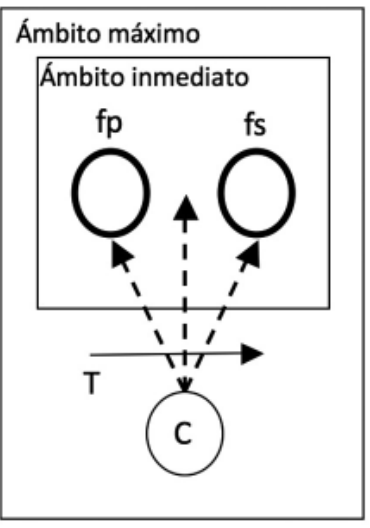

Figura 3.

Subjetivización 
En las tres figuras, la flecha punteada representa el trabajo mental del conceptualizador (C) que se desarrolla a lo largo del tiempo (T). La única diferencia entre las tres figuras está en la flecha que va de la figura primaria (fp) a la figura secundaria (fs). Es sólida en la figura 1 punteada en la (2) y desaparece en la (3). Mientras que la trayectoria concreta se debilita hasta desaparecer, el rastreo del conceptualizador se mantiene y suple las ausencias de lo concreto. Traugott (1995a, 1995b) sugiere alternativamente una aproximación de corte inferencial que desconoce la omnipresencia de representaciones esquemáticas en los procesos de gramaticalización de Langacker y rechaza, en particular, la noción de trayectoria sugerida por Langacker para la gramaticalización de go "ir" como marcador de futuro. En primera instancia, Traugott examina la primera ocurrencia del verbo go en el Oxford English Dictionary:

7. Thysonhappysowle... was goyng to be broughte into helle for the synne and onlefullustys of her body. (1482 Monk of Evesham (OED go 47b))

'Esta alma infeliz iba a ser llevada al infierno por el pecado y la lujuria de su cuerpo'

El verbo ya es marcador temporal y no parece haber rastros de trayectoria alguna. El inductor del evento está codificado en una frase preposicional oblicua, de manera que la trayectoria ha pasado a segundo plano. La construcción es pasiva, en consecuencia, solo la porción final del evento es prominente, no así la trayectoria. Hopper y Traugott sugieren, en cambio, que lo que go marca es un futuro inminente que se desprende de implicaturas conversacionales según se leen los propósitos de los jueces (83). Tampoco la trayectoria es recuperable en (8), donde la noción de movimiento es incompatible con lo estático del evento:

8. The council sat upon it, and were going to order a search of all the houses about the town. (before 1680 History of Charles II, 164 (HDCET))

'El consejo no hizo nada al respecto e iba a ordenar una inspección de todas las casas del pueblo'

Según Traugott (1995a), tiene más sentido sostener que el significado temporal ha sido convencionalizado. Y de ahí en adelante, las lecturas de corte prag- 
mático obedecen a principios inferenciales, como se puede ver en el ejemplo (9):

9. It seems as if it were going to rain (1890 Cham. Jrnl. [OED goVb]) 'Parece que iba/fuera a llover'

Lo que hay en (9) es una modalización epistémica que, según la autora, nada tiene que ver con la noción de propósito, naturalmente asociable con la de trayectoria. Algo similar parece suceder con el sentido más pragmático de (10) en que la modalización proviene de la duda:

10. An accident has been reported on Crockett Boulevard. This is going to be south of Crockett.

'Un accidente ha sido reportardo en Crockett Boulevard. Más bien va a ser al sur de Crockett'

Sostiene Traugott que distintos procesos inferenciales dan cuenta de las funciones pragmáticas que se desarrollan a partir del significado léxico del verbo sin que parezca necesario apelar a la noción de trayectoria. Sin embargo, la crítica de Traugott no está exenta de limitaciones. Nótese que el ejemplo (7) es de 1482. Suficiente cantidad de años de uso lingüístico habrán corrido para que go se usara primero como verbo de desplazamiento físico y para que perdiera después paulatinamente rasgos semánticos concretos en favor de una representación cada vez más abstracta. Como es bien conocido, las manifestaciones orales anteceden con mucho aquellas que se presentan en lo escrito. El ejemplo del OED presupone siglos de uso de go con significado de trayectoria física. El significado predictivo se desprende precisamente de una relación secuencial en que el castigo se da después y como consecuencia del mal comportamiento del sujeto de la voz pasiva. Lo mismo sucede en (8), donde el orden es necesariamente secuencial (primero el gobierno no hace nada y después ordena una inspección). Y el caso de (9) es del mismo tipo. La expectativa de que llueva se desprende de las condiciones climáticas reconocidas en el momento de enunciación. Si bien la consecuencia es inferida, solo lo es en virtud de que el evento sigue una trayectoria. El ejemplo (10) no es menos secuencial. La noción de trayectoria abstracta opera ahora en el nivel ilocutivo según la corrección se establece sobre un antecedente en el hilo del discurso. Lo anterior sugiere que, si bien puede haber lecturas infe- 
renciales, no por ello la noción de trayectoria deja de operar en la base para garantizar una interpretación adecuada. Nótese, por otra parte, que, de no contar con dicha trayectoria, no habría principio alguno que impidiera que la interpretación cambiara en cualquier dirección. La organización lógica entre los distintos significados de go se preserva en virtud de que hay una imagen esquemática de trayectoria a la que todos se apegan.

Los riesgos de dejar que la interpretación inferencial obvie el análisis semántico responden a tres problemas fundamentales. Por una parte, la interpretación puede no ser suficientemente específica, o bien puede carecer de restricciones que eviten que la polisemia se dispare en cualquier dirección y, en última instancia, puede suceder que los significados no cuenten con una motivación que les dé sentido. Ilustraré estos tres riesgos con base en trabajos previos sobre dos marcadores: claro (Maldonado 2010) y según (De la Mora y Maldonado). Se trata de dos fenómenos radicalmente distintos por cuanto la conformación sintáctica de cada forma determina comportamientos distintos. Mientras claro como adjetivo impone su perfil sobre la forma que modifique y puede cambiar de funciones según opere como adverbio o como miembro de distintas colocaciones y construcciones sintácticas, el carácter relacional de según estará restringido en principio por los elementos que relaciona. Intentaré mostrar que la representación esquemática de la forma de base prevalece a pesar de que el significado central sufre un proceso de atenuación que involucra la participación incremental del conceptualizador. Esto sucede tanto en sus cambios polisémicos conceptuales como en sus adecuaciones pragmáticas. Los procesos de atenuación que se presenten tendrán las propiedades que les impone el nivel en el que operen (Hummel), pero el esquema de base se preserva tanto en la polisemia como en la polifuncionalidad de cada forma.

Los datos de ambos estudios provienen del Corpus Sociolingüístico de la Ciudad de México (CSCM) y del Corpus de la Real Academia Española (CREA).

\section{ATENUACIÓN EN CLARO}

No hay duda de que claro es uno de los marcadores discursivos del español que presenta mayor polisemia. Quizá sea pertinente revisar si tal polisemia obedece a factores exclusivamente inferenciales o si intervienen también procesos de atenuación semántica. En este apartado se revisan ambas opciones. 


\subsection{Significados inferenciales}

Distintos investigadores han mostrado el carácter inferencial de la multiplicidad de significados de claro. Así (Briz; Martín Zorraquino; Martín Zorraquino y Portolés; Pons), coinciden en reconocer que claro en (11) es asertivo, en (12) reiterativo, en (13) evidencial y en (14) concesivo:

11. Usted, claro, sabe dónde está la plaza del Pilar, ¿verdad? [asertivo] (apud Martín Zorraquino y Portolés)

12. Claro, mujer, ¿quién te ha robado el bolso? [reiterativo] (apud Martín Zorraquino y Portolés)

13. Claro, siendo la noche cerrada en este sitio no se ve nada [evidencial] (apud Martín Zorraquino y Portolés)

14. Esta es la habitación más bonita de toda la casa... Ahora, claro, ya está estropeada del trajín... ¡Vienen tantos huéspedes en verano! [concesivo] (apud Martín Zorraquino y Portolés)

Freites Barros señala, además, una gama de valores metadiscursivos como los de (15) a (17). Estos usos esparcen sus posibles significados en distintos rumbos. Mientras (15) es de aceptación, (16) es de rectificación y (17) de autocorrección:

15. A: cuénteme de la paradura

B: Claro, aquí hacen fiestas de paraduras... que la gente como promesa tienen la paradura, ¿no? [aceptación] (apud Freites Barros)

16. B: $\mathrm{Y}$ es... ya mayor, porque no es muy joven A: no pues claro, es un hombre ya de cierta... o sea... no, no... [rectificación] (apud Freites Barros)

17. A: Estás diciendo que ni pudiste llegar aquí ayer al trabajo.

B: No, este... claro, el problema fue que ... o sea por la vía [autocorrección] (apud Freites Barros)

Y falta, además, una amplia gama de usos más desemantizados, de corte dialógico, que pueden significar, dependiendo de la entonación y de otros factores contextuales, amenaza o reclamo (18) o, incluso, pauta de continuidad o marca de cambio de turno (19): 
18. Llega cuando quieras; claro, como yo no te importo! (CREA México, 2004)

19. I: porque así entra/ la que sale/ o sea/ es más/ difícil/ <pero pues también> así de caro/ ¿no?/ bueno/ que una casa es igual E: claro/ oye/ yo me acuerdo que esa tenía/ gimnasio y alberca/ ¿no?/ abajo el dep-/ el edificio (CSCM México, 2011)

Todos estos usos sin duda existen y de hecho la lista puede extenderse en forma considerable, pero la pregunta es si tal variedad representa cambios de significado o son más bien sentidos con el mismo significado de base. Existe el riesgo de asumir que se trata de una forma cuyos significados se disparan en todas las direcciones posibles, una "polisemia salvaje". De ser esto cierto, ratificaríamos el viejo prejuicio de que el significado no es controlable y es, simplemente, caótico. La otra opción sería asumir que, si bien la complejidad del fenómeno es notable, existe la posibilidad de sugerir algunos principios básicos que gobiernen y acoten la formación de tal variedad de empleos. Sugeriré que la formación de los valores pragmáticos y metadiscursivos antes descritos se desprenden del significado de base del adjetivo claro, cuyo valor nuclear sufre una serie de cambios que obedecen a un continuo proceso de pérdida de rasgos semánticos y a una adopción incremental de propiedades pragmáticas que, en el fondo, corresponden a distintos niveles de subjetivización (Langacker 1990, 1985) e intersubjetivización (Nuyts 1993, 2001; Cornillie 2004, 2008). Tanto las extensiones de significado como sus restricciones están determinadas por procesos de atenuación semántica, en el sentido de Langacker, que abren el espacio para la intromisión de la mirada del conceptualizador. De manera fundamental, sugeriré que el significado de base de la forma léxica se preserva en forma esquemática incluso en los casos más pragmaticalizados. Tal esquema garantiza que la expansión de sentidos esté acotada y que sus desarrollos pragmáticos preserven la estructura del significado de base. En coincidencia con Hummel, propongo que los cambios de significado están determinados por relaciones sintácticas específicas. De manera más concreta, intentaré demostrar que los cambios de significado de claro responden a tres fenómenos fundamentales: 1) dislocaciones de la forma léxica que llevan a representaciones subjetivas, 2) significados que emergen como producto de colocaciones que se cristalizan en términos construccionales y 3 ) procesos de atenuación semántica en que la subjetividad determina la interpretación contextual. 


\subsection{Significado de base}

Los datos de claro, tomados del CSCM y del CREA, suman cerca de tres mil entradas. No haré aquí un tratamiento estadístico de la muestra. El significado de base se asocia fundamentalmente con la presencia de la luz como garantía de acceso visual. Ese es el significado que consigna tanto el diccionario de Moliner como el DRAE. La mayoría de las acepciones que les siguen son instancias específicas o extensiones predecibles de ese significado central. Los colores (20) y las condiciones atmosféricas (21) claros contrastan con los oscuros, por tener luz:

20. L.C. Chadwick afirma que las hojas verdes-claro contienen los nervios más claros que la superficie (CREA México, 1994)

21. desde la base envían señales cuando hay niebla o en tiempo claro. Estas señales pueden ser captadas a bordo del barco (CREA México, 2002)

Todos los casos de nominalización (un claro en medio del bosque) que aparecieron en el corpus corresponden a lo que el DRAE define como un 'Espacio sin árboles en el interior de un bosque', es decir, una zona visible con luz. Llevado esto a ámbitos abstractos se obtiene el valor adverbial (22) que, aunque apenas si ocurre en el corpus, comparte tanto con la forma adjetiva/predicativa (2224), como con la sustantiva: la propiedad de ser fácilmente perceptible, ya sea visual, auditiva o mentalmente. No hay obstáculo que se interponga entre el objeto de conceptualización y el conceptualizador:

22. La imperiosa necesidad de sacar la voz, de cantar alto y claro... sin detenerse en los infinitos matices de los versos (CREA México, 2002)

23. (En la radio) La información o mensaje debe ser claro y con menos palabras que los artículos periodísticos. (CREA México, 1995)

24. Punto que aparece claro cuando se señala el fin primordial de PROIDES: mejorar la calidad de la educación superior. (CREA México, 2004)

La percepción sensorial pasa a segundo plano para permitir que la actividad mental constituya la figura principal del evento. Esta extensión coincide con tendencias naturales de cambio semántico bien conocidas (Lakoff 1987; Lakoff y Turner; Langacker 1991; Traugott 1995, 1988 y muchos otros a 
partir de ellos), en que los significados concretos tienden a desarrollar una representación abstracta.

\subsection{Significados construccionales}

Muchos de los significados que se reconocen en claro se presentan en colocaciones o en construcciones que de una u otra manera subrayan la transparencia o la evidencia de algo que se asevera. Si bien los significados cambian de construcción en construcción, lo que más llama la atención es que el significado de base de claro se mantiene prácticamente intacto.

\subsubsection{Construcciones constatativas}

El significado abstracto-mental de claro ha generado distintas construcciones cuya configuración esquemática es prácticamente la misma: se trata de eventos mentales que son intelectualmente accesibles y que no presentan dificultad u obstáculo alguno para ser entendidos. Las construcciones se presentan con verbos como dejar (en), quedar (en), resultar, tener y quedar. El significado básico del adjetivo no deja de ser el de 'acceso mental sin dificultad'; los contrastes entre estas construcciones están determinados por la forma verbal. Mientras dejar (en) claro (26), señala el carácter declarativo de lo que se afirma, verbos como quedar, sacar, tener y poner lo hacen a partir de actos no necesariamente declarativos. Lo que no se declara, se pone a la luz (27), se devela (28) y, en casos esporádicos, se tiene a la vista. En todos estos casos, un evento o una idea se constituyen como hechos fácilmente perceptibles:

25. Antes de seguir adelante, Miss Clarisa, quiero dejar claro que yo no le pedí al doctor Zavala la jefatura de quirófanos; él me llamó para proponérmelo. (CREA México, 1991)

26. ... debería matar o capturar a un solo español, para poner en claro contra quiénes combatía, si eran hombres o dioses. (CREA México, 2002)

27. Lo único que se saca en claro es que Martín Cortés en sus años mozos, habría sido un hombre de armas que militó en el bando perdedor. (CREA México, 2002)

28. ... tenemos que tener en claro que a través del tiempo se le han dado a Seis Sigma diferentes enfoques en el medio industrial. (CREA México, 2004) 
Todas las construcciones hacen que una declaración se dé por sentada, que se tome como incuestionable en virtud de que constituyen hechos verificables. Las diferencias aspectuales de puntualidad y duratividad, o el carácter resultativo de la validación con verbos como resultar o quedar han sido objeto de otro trabajo (Maldonado 2010).

El comportamiento de claro, sea como adjetivo, sustantivo, adverbio o en construcción verbal fija, preserva el núcleo sémico de acceso perceptual o mental a un objeto físico o mental en el que no interviene obstáculo alguno. Los ajustes de adjetivo a adverbio son los esperables. Como sustantivo o adjetivo hace referencia a las propiedades del sustantivo como entidad con propiedades fácilmente perceptibles, como adverbio a la manera libre de obstáculos con que un experimentante establece contacto con tal tipo de objeto. La polisemia observable en claro obedece a la atenuación de algún rasgo físico o perceptual de la forma de base (la representación física) y ello conlleva una evolución conceptual predecible que va de la accesibilidad visual a la intelectual, como se esquematiza en la escala 1 :

\section{Escala1}

luminosidad > acceso perceptual sin obstáculos > acceso mental sin obstáculos.

Tal evolución conceptual parece haberse esquematizado, en forma de la Figura 4, según la cual claro corresponde a un significado de acceso perceptual o mental libre de obstáculos que un experimentante tiene con respecto a un objeto, ya sea concreto o abstracto:

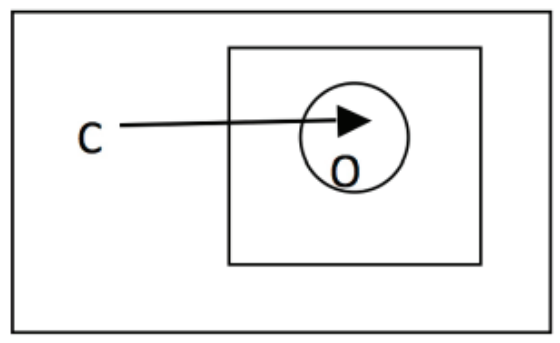

Figura 4. Significado esquemático de claro

Este significado general constituye la base conceptual para una serie de valores de corte pragmático en los que la presencia subjetiva del conceptualizador 
cobra mayor peso. Las construcciones con verbos como dejar (en), quedar (en), resultar, tener y quedar presentan un hecho como incuestionable, lo validan como verdad existente en el espacio del discurso. Estas construcciones anuncian los usos de claro más claramente evidenciales.

\subsubsection{Construcciones evidenciales}

El valor evidencial de claro ha sido ampliamente reconocido en estudios contemporáneos del español (Briz; Martín Zorraquino; Martín Zorraquino y Portolés). Son evidenciales en virtud de que operan como formas gramaticales o recursos discursivos que codifican la actitud del hablante respecto de la validez de la fuente informativa del mensaje que introducen (Aikhenvald; Chafe). Hay una serie de usos que se dan, ya en lo oral, ya en lo escrito, en que se manifiesta la validación de una afirmación hecha por el hablante. Quizá sea pertinente subrayar que la frontera entre el valor de base y el evidencial es verdaderamente sutil. Esto es notable en construcciones de predicado nominal como es claro, parece claro, resulta claro, está claro, que validan la evidencia del contenido de la oración que les sucede. El caso evidencial más prominente es el de está claro:

29. ¿No se encontró en la antesala de Reagan a destacados personajes del Partido de Acción Nacional? ¿No son los mismos conservadores de antaño que buscan el apoyo Papal o los mismos que trajeron a Maximiliano? ¿No son los ultraconservadores de siempre? ¿Está claro quiénes han tratado de enajenar la soberanía nacional a lo largo de nuestra historia? (CREA México, 1994)

Si bien claro designa su significado de base, en la construcción sobresale el hecho de que la pregunta es de carácter retórico. El hablante no solo da por consabida la respuesta, sino que hace responsables del estado del país a los miembros del Partido de Acción Nacional. Los cambios del valor de base a los de corte evidencial sugieren un proceso doble de pérdida de rasgos (atenuación semántica, en el sentido de Langacker) y de reforzamiento pragmático. La claridad del hecho deja de depender de las propiedades del hecho en sí y está validada, en cambio, por el discurso del hablante.

En estas construcciones cabe destacar que la validación se presenta como legítima para cualquiera. Las sutiles diferencias entre estas construcciones evi- 
denciales es el grado validez subjetiva/intersubjetiva con que se presenta un hecho. En otro trabajo (Maldonado 2010), he sugerido que el carácter subjetivo o intersubjetivo de estas construcciones está determinado fundamentalmente por las propiedades semánticas de los verbos que acompañan a claro. Una escala de (inter)subjetividad ubicaría estas construcciones de la siguiente manera:

Subjetividad Intersujetividad

estar claro $>$ parecer claro $>$ resultar claro $>$ ser claro

Tabla 1. Intersubjetividad en construcciones con claro

En virtud de que un hecho se presenta como válido para el conjunto de personas inmersas en una situación determinada, en un grupo social o en una comunidad hablante, su valor es intersubjetivo (Nuyts 1993, 2001; Cornillie 2003, 2008). De lo contrario, una validación subjetiva del evento reflejaría con mayor claridad la mirada del conceptualizador. Los argumentos que distinguen los contrastes graduales entre construcciones se encuentran en otro trabajo (Maldonado 2010), sin embargo, los ejemplos reflejan la forma en que contrastan con suficiente nitidez. Mientras que con ser (30) y resultar (31) la representación es dominantemente intersubjetiva, con parecer (33) la presencia del conceptualizador tiene mayor prominencia:

30. Es decir, la innovación y la síntesis del proceso innovativo son entre los factores que estadísticamente impactan mayormente al desarrollo económico, subordinando la importancia de lo geográfico, lo institucional o lo demográfico. Es claro que tal innovación resulta extremadamente costosa y los recursos requeridos al igual que en otros procesos son escasos. (CREA México, 2004)

31. Cuando la angustia y la tensión se vuelven crónicos, se "somatizan", es decir, producen cambios fisiológicos crónicos, como un aumento en la tensión muscular, frecuencia cardiaca... Resulta claro que este aumento en la actividad fisiológica es incompatible con el inicio y mantenimiento del dormir. (CREA México, 1998)

32. Podemos dar por hecho que la percepción social de las crisis ha sido modelada sobre la base de la heterogeneidad política e ideológica que afecta a toda la formación social mexicana. En consecuencia, parece 
claro que toda estrategia para enfrentar la difícil situación económica y sus repercusiones políticas, no tendrá éxito si soslaya estas diferencias a la hora de definir e instrumentar las respuestas. (CREA México, 1990)

Es indudable que la afirmación depende del punto de vista del hablante, pero parece ser que esa es la situación de base. En una afirmación cualquiera como Fuan es inteligente está de entrada la calificación del emisor [Yo pienso que Juan es inteligente] (Verhagen; Langacker 1990); sin embargo, el nivel de prominencia de la mirada del conceptualizador aumenta de (30) a (32). En (30) el antecedente es una construcción de predicado nominal que representa como verdad asumida que la innovación y la sintesis son los factores de mayor impacto. Con base en esa afirmación, dada como hecho, el consecuente costo de llevar a cabo tal innovación es indudable no solo para el emisor, sino para cualquier persona que observe los mismos factores. En cambio, con resultar y parecer es cada vez más evidente que se trata de una deducción del hablante. La construcción en (32) es de alta recurrencia en discurso argumentativo (Maldonado 2010), según el hablante defiende una idea a lo largo del párrafo. Los antecedentes de claro incluyen la primera persona del plural podemos/volvemos en que el emisor sostiene una idea e incorpora a los lectores/oyentes para que compartan su punto de vista y aprueben su aseveración. Lo anterior es acorde con la observación de que parecer facilita constructos subjetivos. En discurso argumentativo, es común que parecer acepte la adición de marcadores de dativo (me/nos/te parece claro) que introducen la mirada del conceptualizador en el evento (Maldonado 2002).

De los verbos que entran en esta construcción, estar es sin duda el que manifiesta el nivel más alto de subjetividad:

33. ¡Este le debía su elección al sindicato del crimen! Por esa razón agradece la lealtad demostrada por Costello de una manera muy sumisa. Está claro que el mafioso compartía su bolsillo a este juez supremo (CREA México, 2003)

34. Éste es el momento apropiado para destacar la importancia tan grande que tuvo la intervención de Martín Cortés, pues de no haber revertido éste la situación, neutralizando a Fonseca, está claro que los acontecimientos hubieran tomado un sesgo muy diferente (CREA México, 2002) 
Marcado con tercera persona, la primera lectura que se debería obtener sería la de algo evidente para todo el mundo; sin embargo, es notorio que con estar se devela una imprecación, una acusación por parte del hablante que se ofrece para que el receptor se sume a ella.

La caracterización subjetiva de estar (claro) en contraste con el carácter cuasi-universal o intersubjetivo de ser (claro) coincide con caracterizaciones anteriores en que en estar se reconoce la presencia del conceptualizador en el evento (Delbecque). Si las observaciones hasta aquí hechas son correctas, se puede sugerir que, en estas construcciones, claro opera sistemáticamente como marcador evidencial en virtud de que designa conceptos a los que se tiene acceso en forma nítida, lo cual licencia procesos de validación; pero su carácter subjetivo o intersubjetivo está determinado fundamentalmente por las propiedades semánticas de los verbos que lo acompañan.

\subsubsection{Subjetividad no construccional}

El desarrollo de una serie de significados con distintos niveles de subjetividad parece desprenderse de dos factores: la dislocación sintáctica de claro y las ruptura de relaciones valenciales entre claro y su núcleo nominal (Maldonado 2010). En ambos casos, el significado de claro deja de estar anclado en las propiedades reconocibles en el objeto, para darle mayor prominencia a la presencia evaluativa del conceptualizador.

A partir de Bolinger, autores de distintas corrientes (Halliday; Quirk; Athanasiadou; Shindo; Paradis; Maldonado 2010) han observado que la dislocación genera lecturas subjetivas que incorporan la valoración del hablante. Así, en criminal old lawyer se trata de un abogado viejo que es visto como criminal, mientras que en old criminal lawyer se trata de un abogado criminalista que es viejo. El adjetivo que está más cerca del sustantivo resalta sus propiedades intrínsecas; el que está más lejos del núcleo es más subjetivo y le da prominencia a la mirada del conceptualizador. Este mismo fenómeno se presenta en el español. Los casos de dislocación del adjetivo, en que antecede al nombre en vez de sucederlo, se corresponden consistentemente con fenómenos de subjetivización. Cuando claro sucede al núcleo resaltan las propiedades intrínsecas del sustantivo; cuando lo antecede, la atención se centra en el carácter incuestionable, indudable, de las propiedades del sustantivo según las reconoce la mirada del hablante: 
35. El equipo de trabajo contó con la colaboración de GuiBonsiepe, Werner Zemp y... precursores de una cultura material propia y con un claro sentido social en su trabajo. (CREA México, 1992)

36. Ofrecen un incentivo dinámico y permanente para continuar reduciendo los niveles de contaminación... En particular, constituyen un claro incentivo para que las empresas con costos de control relativamente bajos adopten el máximo posible de medidas paliativas. (CREA México, 1999)

En contraste, si el adjetivo sucede al núcleo (un sentido social claro, un incentivo claro) lo que resalta son las propiedades intrínsecas del "sentido social" o del "incentivo", independientemente de la mirada del hablante.

Por otra parte, los casos de conflicto valencial generan también lecturas subjetivas. Si los rasgos del adjetivo y el sustantivo coinciden, se resaltan las propiedades intrínsecas del sustantivo modificado. En cambio, cuando hay conflicto de propiedades entre ambos miembros, es trabajo del conceptualizador promover una interpretación posible. Un plan perfecto contrasta con un perfecto idiota. $\mathrm{Al}$ no haber traslape entre adjetivo y sustantivo, perfecto opera como intensificador de grado máximo según la apreciación del conceptualizador. La polisemia del adjetivo está determinada, entonces, por las propiedades del sustantivo (Paradis). Sin pérdida de rasgos, sin atenuación semántica, hay modificación. Cuando las propiedades del adjetivo no son aplicables a las de los sustantivos, su representación cambia de nivel y se proyecta a la valoración pragmática que impone el hablante. Hay intensificación subjetiva, como la que se puede observar (37) y (38):

37. ...el enorme poder de ciertos medios de comunicación, el claro interés por mantener a la gente aturdida y desinformada (CREA. México, 2001)

38. esta última donde la dirigencia política exhibe un claro sesgo hacia posiciones más derechistas, definidas con intereses específicos (CREA. México, 1990)

La falta de relación valencial entre sustantivo y adjetivo dispara una lectura subjetiva. No es que el interés o el sesgo sean claros en sí, sino que resultan incuestionables para el hablante. Es de notar que en español el conflicto valencial coincide siempre con la anteposición de claro al sustantivo. Aquí, tanto el análisis de atenuación, a la Langacker, como el de desarrollo de inferencias, 
a la Traugott, ofrecen una explicación adecuada. Los rasgos de "fácil accesibilidad" característicos de claro se debilitan en favor de un reforzamiento pragmático.

\subsection{Sentidos pragmáticos}

He mostrado que los cambios de significado de claro se dan ya por aparecer en colocaciones, ya por dislocación. Cabe preguntarse ahora bajo qué circunstancias se dan los sentidos eminentemente pragmáticos.

\subsubsection{Activación de inferencias}

Las construcciones anteriores pueden diferir en grado de subjetividad; coinciden, sin embargo, en su consistente apelación al conocimiento compartido. En la construcción está la presuposición de que tal conocimiento debe estar a la mano para el interlocutor, sea, este el oyente, o un grupo perteneciente al mismo dominio cultural. Para que se activen tales presuposiciones solo es necesario asumir que aquello que es claramente perceptible o conceptualizable para el hablante, lo es también para el oyente y para los demás. La Figura 5 representa dicha base conceptual. De esa representación esquemática se puede observar que la base semántica de "acceso sin obstáculos" expuesta en la Figura 4 sigue siendo válida y, a diferencia de la Figura 5, más que resaltar la prominencia de un elemento respecto de otros que permanecen en la base, sobresale el libre acceso al objeto perceptual, e incluye además, la presencia del receptor (R) individual o grupal (el círculo punteado que rodea a $\mathrm{R}$ ), a quien el emisor incorpora en la validación de un hecho consabido. Tal incorporación es asimétrica. El emisor retoma lo afirmado en el turno anterior por su interlocutor para reafirmarlo y proceder con distintas fases argumentativas en que incorpora al oyente:

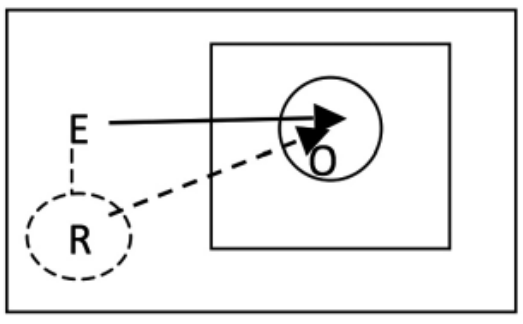

Figura 5. Evidencial 
De esta representación se deriva una serie de usos pragmáticos en que se retoma consistentemente el conocimiento compartido y, a partir de él, se expande o se corrige la información presupuesta.

Mientras que todos los significados hasta ahora vistos se dan como consecuencia de colocaciones, construcciones o dislocaciones, queda, sin duda, una amplia gama de sentidos pragmáticos o metadiscursivos (Freites Barros), cuyo contenido deberá ser analizado en términos presuposicionales. Quizá el uso más frecuente sea el (auto)correctivo. El hecho de que exista ya cierto conocimiento en la comunicación genera significados sujetos a modificación. La información asumida puede ser errónea, o bien insuficiente para llegar a determinada conclusión. En ambos casos la información que sucede a claro rectificará las conclusiones a las que debería llevar la información presupuesta. El paso que anuncia la corrección es la marcación de una afirmación como obvia, sea ella correcta o no. En este sentido es pertinente subrayar que la mayoría de los usos encontrados en el corpus son autocorrectivos. Ahora bien, no es claro la forma que establece la corrección. Los marcadores adversativos, como pero, sin embargo o una fuerte configuración entonacional se encargan de hacerlo. A claro solo le corresponde sentar la base compartida por hablante y oyente para que su contenido sea rectificado:

39. I: sí pues < pus> sí/ más bien de lo que es raí-/ nuestras raíces y// y aparte otras culturas

E: órale/ [de eso] una parte que has vivido/ ¿no?/ y además otra que traes ya hace m-/ desde hace muchos años/ ¿no?

I: claro/ pero también la/ fíjate que// en la cuestión de/ de música [CSCM México, 2011)

Si la combinación de claro+pero es común, lo es más la codificación del significado correctivo en la construcción claro que, la cual presenta diferencias sutiles de uso. En el caso de (40), anticipa la potencial objeción que el interlocutor podría tener respecto de una afirmación hecha y se encarga de corregirla en forma anticipada:

40. Yo pensé y lo sigo creyendo, que él y usted se parecían mucho. Claro que es un parecido largo de explicar (apud Martín Zorraquino y Portolés) 
La corrección puede tener además tonos enfáticos que permiten subrayar algo que se ha puesto en duda:

41. ... claro que puedo hacer el diagnóstico de alcoholismo en una persona, ...que yo no pueda hacer algo por él porque niega su enfermedad, ya es otra canción. (CREA. México, 2011)

Este tipo de usos muestra otra cara importante del contenido de claro, aquella en que el contenido presuposicional es reforzado de manera importante. Y ese mismo tipo de refuerzo se obtiene en la construcción claro está que. Nótese que la lectura subjetiva se obtiene por la anteposición de claro al verbo, fenómeno ya analizado en el apartado (II. 4) Subjetividad no construccional. Su uso como marcador pragmático se desprende del conocimiento compartido con el interlocutor para ratificar un punto de vista (42), o hacer aclaraciones anticipatorias a posibles objeciones (43). Su función como marcador pragmático responde a la carga subjetiva que impone el emisor:

42. En el caso del lenguaje religioso, claro está, lo importante es que su aplicación genera, refuerza, promueve actitudes, sentimientos, emociones peculiares. (CREA México, 1993)

43. La educación debe de ser moral tanto en nuestros países como en cualquier parte del mundo, son valores y virtudes universales, fuera del tiempo y del espacio, pero claro está que deben armonizar con nuestra idiosincrasia. (CREA México, 1995)

Como marcador pragmático estas construcciones resaltan la intención del emisor de garantizar que se asuma el conocimiento compartido como base para la comunicación. Obsérvese, sin embargo, que tal conocimiento solo existe en virtud de que está al alcance del hablante y el oyente. El perfil subjetivo de la construcción se da en virtud de que lo afirmado depende más de la validación del hablante que de la veracidad de los hechos en sí. La base esquemática del adjetivo se preserva, mientras la construcción impone perfiles particulares. 


\subsubsection{Conector dialógico}

Los usos de claro como simple conector dialógico tienen el mismo tipo de configuración que la construcción claro está. Claro es un marcador anafórico que valida eventos a partir del conocimiento compartido entre emisor y receptor. El significado esquemático de la base adjetiva de "acceso fácil a una idea o una afirmación" se mantiene, aunque en forma diluida, y se limita a adoptar como válida la declaración sobre la que tiene alcance. El rasgo más sobresaliente de claro en el discurso dialógico es que su antecedente es la emisión previa de un interlocutor al que el emisor responde:

44. I: hacerle este/ volumen y todo/ brillo/// y él le puso un/ un gris/ que parecía una/ plasta/ no sé de qué/ o sea estaba mal hecho/ estaba mal $\mathrm{E}: \mathrm{mh}$

I: pero/ obviamente les hace falta más cerebro

E: claro más visión

I: exactamente/ o sea ... (CSCM México, 2011)

Ante la falta de un antecedente expreso, la expresión de claro es, por definición, poco elaborada. Se trata de una versión aún más atenuada del significado de 'acceso fácil al contenido de la información compartida'. A falta de marcas sintácticas o construccionales, es aquí donde el empleo de pautas suprasegmentales hace que se multipliquen los valores de claro. Remiten a distintas fuentes de mayor o menor obviedad desde donde el conocimiento compartido entre hablante y oyente puede emerger. Sobre estos usos hay ya abundantes análisis pragmáticos (Briz; Martín Zorraquino; Freites Barros; Martín Zorraquino y Portolés; Pons). En consecuencia, me limitaré aquí a hacer algunas anotaciones mínimas, no sin subrayar que el significado esquemático de claro se preserva, y que las funciones pragmáticas están impuestas por pautas entonacionales.

En su forma más simple, la información que está en juego es evidentemente compartida por hablante y oyente. En otros casos se retoma lo dicho por el interlocutor como obvio para elaborarlo en mayor detalle:

45. I: no/ o sea/ me/ me refiero en que/ bueno// yo apenas voy comenzando inglés y y// sé que al rato lo voy a/ lo voy a entender// pero tampoco sé q-/ tambi-/ también sé que no/ no debo de// de con- 
fiarme/ y sobre todo de que tengo que hacer hincapié en/ en eso de tratar de entenderlo auditivamente

E: claro/ pues < pus>/ lo que podrías hacer es cuando veas películas en inglés// le tapas los subtítulos/ entonces así como que [tratas de]

I: [(risa)]

E: y [además sí]

I: [no le entiendo nada]. (CSCM México, 2011)

En muchas ocasiones claro se usa para señalar que el contenido de lo dicho por el interlocutor tiene tintes de redundancia. Martín Zorraquino y Portolés sugieren que una de las funciones de claro es introducir una porción de discurso como si ya fuera repetida. La simple repetición de claro marca no solo el acuerdo sobre lo dicho por el interlocutor, sino que enfatiza su obviedad:

46. I: o sea para que sepas/ ¿no? lo que es...bueno pues... un, un tatuaje bueno ¿no?

E: claro/ claro (CSCM México, 2011)

Por su parte, las pautas entonacionales activan distintos tipos de inferencias. Me limitaré a señalar unas cuantas. Con tono descendente (H-L), claro se usa para dar la razón sin reservas:

47. I: [jugábamos/ veíamos]/ no/ mm/ bueno/ sí llegamos a/ tener algunos accidentes/ pero no aquí en Tepito sino/ allá donde vivíamos antes... quieras que no/ así como que te aíslas un poco de la gente/ porque pues no compartes lo mismo E: claro (CSCM México, 2011)

Con tono primero alto y luego descendente (H-HL), claro puede usarse para indicar que viene a la mente algo que se había olvidado y que resultaba obvio:

48. I: así/ es de lo que más me acuerdo de la/ y ah/ jclaro!/ tuve mi grupo de niños ahí de/ de amigos/más bien/ ahí en aeropuerto/ cuando me cambié allá/ allá por este// ¿cómo se llama?// bueno/ ahí ya tiene// mucho tiempo que// me quedé// (CSCM México, 2011) 
Puede también indicar la aceptación a una petición (Freites Barros). En estos casos la entonación va del tono medio al descendente (LH):

49. A: cuénteme de la paradura

B: Claro. Aquí hacen fiestas de paraduras... que la gente como promesa tienen la paradura, ¿no? (apud Freites Barros)

Quizá no exista mejor manera de hacer reclamos que la de emplear claro para asumir como cierto aquello que se identifica como ofensivo. Pero es evidente que el reclamo no está en claro, sino más bien en el contenido de la cláusula reclamativa. El marcador se encarga de enfatizar lo obvio ya sea de un reclamo (50), ya de la causa incuestionable de una situación (51):

50. Llega cuando quieras; claro, ¡como yo no te importo!

51. Se van en el mismo coche, claro, como viven cerca.

En forma más desemantizada, en la conversación se emplea dominantemente como marca de cambio de turno. Su empleo en el diálogo se desprende de la base misma de claro: aquello que ha dicho nuestro interlocutor es ya sabido, $y$ es adecuado que el hablante tome el turno comunicativo para aportar nueva información. Las variaciones aquí son sutiles. En unos casos, como sucede con ya (Delbecque y Maldonado), el empleo de claro, con tono bajo, puede ser la pauta para que el emisor calle, para que cambie de tópico o para tomar el turno en la conversación:

52. I: porque así entra/ la que sale/ o sea/ es más/ difícil/ < pero pues también> así de caro/ ¿no?/ bueno/ que una casa es igual $\mathrm{E}$ : claro/ oye/ yo me acuerdo que esa tenía/ gimnasio y alberca/ ¿no?/ abajo el dep-/ el edificio (CSCM México, 2011)

En casos opuestos, claro es pauta para que el interlocutor siga hablando. Aquí el tono no solo es medio, sino que la emisión de claro es neutra y carece de énfasis. Se trata de una emisión un tanto mecánica que evita interrumpir el discurso del interlocutor:

53. I: ...la escuela no te va a dar todo/ tú lo tienes/ tú tienes que aprender un buen por tu parte 
E: claro

I: desarrollarlo/ practicarlo/ estar sobre sobresobresobresobre

E: claro (CSCM México, 2011)

Y en los casos aún más desemantizados, puede reducirse a una simple marca para mantener el contacto entre los interlocutores:

54. I: estaba estacionado pero yo saqué la punta/ y él como vio que estaba estacionado/ se dio la vuelta muy cerrada

E: claro

I: si me ha visto/ pues < ps> él la da más abierta/ ¿no?// y total que ya me pagó (CSCM México, 2011)

En estos usos, es incluso posible ver que el significado de base del adjetivo permanece como plataforma sobre la que se manifiesta la amplia gama de usos pragmáticos que lo caracteriza. Dada la claridad, la ausencia de dificultad para procesar la información compartida por hablante y oyente, los cambios suprasegmentales se encargarán de instalar pautas inferenciales distintas.

Los datos de claro sugieren que la atenuación semántica motiva la emergencia de interpretaciones pragmáticas. La preservación de la base semántica de la forma proporciona las bases para que el fácil acceso al conocimiento compartido pueda ser empleada con funciones distintas. En todas ellas el presupuesto de que se trata de información que tanto hablante como oyente deben compartir permite su cálculo pragmático en circunstancias distintas.

\section{SEGÚN. UNA DEPENDENCIA ATENUADA}

Esta sección se encarga de revisar una atenuación semántica que lleva a otro tipo de revelaciones pragmáticas. El objetivo es mostrar que la calidad semántica de la forma de base determina el tipo de representaciones pragmáticas que se dan, conforme se diluye su configuración semántica. El contraste entre el comportamiento de claro y según mostrará que la preservación parcial del contenido semántico determina los desarrollos pragmáticos de cada una de estas formas léxicas. A pesar de que según es un conector, su comparación con el adjetivo claro es pertinente porque ambas formas desarrollan valores evidenciales, pero, dada su configuración gramatical de base, ponen en relieve perfiles notablemente diferentes. 


\subsection{Marcador evidencial}

En contraste con lenguas que cuentan con formas gramaticales para marcar la fuente informativa de una aseveración, el español cuenta apenas con algún marcador incipiente de evidencialidad, como es el caso de que (Demonte y Fernández-Soriano), así como dizque y quesque, para México y algunos dialectos de América (Miglio; Olbertz; De la Mora y Maldonado), por lo que es de esperar que la lengua desarrolle una serie de estrategias discursivas evidenciales que sirvan para validar la confiabilidad de la fuente informativa de una emisión (Aikhenvald); esto es, para dejar saber si la información aportada es obtenida por contacto directo, reportada por otros o adquirida de manera menos definida. Este es el caso de según, considerado por González Vergara como una entre varias estrategias discursivas del español para codificar evidencialidad:

55. Según el censo 2002, el 26,8\% de los hogares chilenos tiene conexión a internet con banda ancha. (apud González Vergara 2011)

Según ha sido definido como un marcador evidencial en sentido estricto, por cuanto al usarlo el emisor no designa más que el contenido de su fuente informativa (Alonso Almeida y Adams). Esto sucede tanto en (55) como en el ámbito de los reportes médicos en que lo declarado retoma integralmente el contenido de investigaciones previas o de evidencias reunidas en una investigación:

56. Según los resultados de dicho estudio, el salario mínimo SM aumenta 4 veces el riesgo de nuevas complicaciones cardiovasculares. (apud Alonso Almeida y Adams 2012)

Los autores declaran que esta restricción se da particularmente en el ámbito de los reportes científicos. La consideración de mayor rango de contextos aporta otros usos evidenciales más laxos: rumores (57), usos de alcance restrictivo (58), e incluso usos epistémicos en que se duda de la verdad de lo dicho (59):

57. Según se rumora si no refinamos gasolina aquí/ ¿qué podemos hacer? (CSCM México, 2011) 
58. y le digo/ "bueno/ a ver/ según tú/ ¿cuánto vale tu libertad?"/ ¿sabes esto cuánto...? (CSCM México, 2011)

59. y me ponía a leer/ según yo me ponía a leer/ ¡y empezaba!/ a deletrear así/ este/ de una en otra letra. [Contexto: el sujeto no sabe leer]. (CSCM México, 2011)

La formación de estos usos encuentra una explicación natural bajo la hipótesis de atenuación semántica, según la propuesta de Langacker expuesta en la introducción de este trabajo. Al igual que con claro, según va perdiendo rasgos semánticos que motivan la participación del conceptualizador. En su representación básica, según opera, sin duda, como marcador evidencial puesto que reproduce el contenido de una fuente informativa. Su significado nace en la forma latina secundum 'según', que es el acusativo fosilizado del gerundio del verbo SEQUI (SEQUOR, SECUTUS SUM) 'seguir'. Como preposición, el DRAE lo define como 'Conforme, con arreglo a'. Esto es, lo introducido por según sigue, reproduce el contenido de su antecedente. Lo más común es operar de acuerdo con reglas, normas, tradiciones y procedimientos bien establecidos:

60. Ahí arranca la acción dramática y se inicia la peripecia, según los cánones de la composición dramática. (CREA México, 1996).

En otro trabajo (Maldonado y de la Mora) hemos sugerido un análisis en términos de espacios mentales (Fauconnier) en que según construye un espacio mental (EM) cuyo contenido (X') ha de satisfacer las condiciones de (X) en el espacio de referencia (R). La Figura 6 ofrece la estructura básica de según:

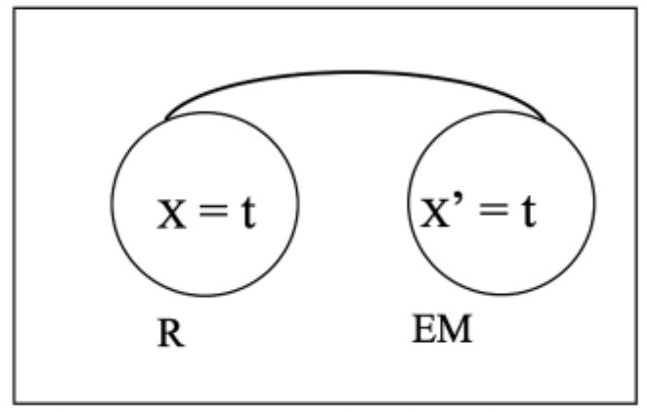

Figura 6. Patrón básico de según 
En la Figura 6, X' en el espacio mental (EM) se adecua al contenido de X en el espacio de referencia (R). Así en (60) la acción de X' se hace en concordancia con los requisitos de la composición dramática en X. Lo importante de esta representación es que sienta las bases para el desarrollo de nuevos significados. Por una parte, pueden emerger nociones de secuencialidad y causalidad:

61. tendría que conformarse con cerveza. El calor aumentaba según el sol ascendía (CSCM México, 2011)

62. El timbre de su voz cambiaba según las preguntas que me hacía (CSCM México, 2011)

Así como el calor cambia según la posición del sol, así las preguntas determinan el timbre de la voz. Es de observar que la secuencialidad temporal garantiza la relación causal. Primero cambia el sol de posición, de igual forma que primero se emite una pregunta para que después procedan los cambios de temperatura o del timbre de voz. R determina el comportamiento de EM, según el espacio mental está ligado al espacio de referencia.

Solo en virtud de que existe esta relación entre espacios se explica la aparición de los usos evidenciales. Su antecedente está en usos reportativos cuyas fuentes son documentos (reportes, contratos, estudios, etc.):

63. ...o sea/ que se murieron/ bastantes gentes/ bueno bastante es decirlo// según ahí dice que se murieron como unas diez (CSCM México, 2011)

Lo que según introduce es precisamente información que procede de su antecedente. La función es idéntica, pero opera ahora en el dominio del discurso. Dado que el referente está compuesto por documentos, la confiabilidad de la fuente es total. Algo similar sucede cuando aquello que se reporta pertenece al dominio común. El significado es ahora intersubjetivo (Nuyts 1993; Cornillie 2008) por cuanto este es compartido por una comunidad hablante y, en consecuencia, la confiabilidad de los datos es alta.

64. y en realidad/ ¡ella!/ según se sabe ahora/ fue informante de/ de Martín Luis Guzmán (CSCM México, 2011) 
El hecho de que se trate de conocimiento compartido reduce la prominencia del conceptualizador en favor de una representación intersubjetiva codificada en forma impersonal (se sabe). El emisor comparte la veracidad de lo dicho con su grupo social. No necesariamente sucederá lo mismo cuando la referencia esté en tercera persona. Si se trata de una autoridad en la materia (65) o una institución (66), la fuente, codificada en tercera persona, puede tener prácticamente la misma validez que un documento. De otra manera, tendrá los efectos opuestos tomará un valor restrictivo al que me referiré más adelante:

65. ya este/ sabemos que es una banda salvadoreña” según él/dice “ ¿hablaban como los de Chiapas?" "sí/ así hablaban" (CSCM México, 2011)

66. cuando estuve en Aseguradora Hidalgo/ me/ me enfermé de las/según me habían informado que tenía yo tres discos dañados (CSCM México, 2011)

Ahora bien, cuando la fuente es difusa, la confiabilidad de lo dicho disminuye considerablemente. Los casos típicos de esto son los rumores con información compartida a voces (hearsay) y el de fuentes no claramente identificadas que carecen de solidez para garantizar la veracidad de lo reportado. Lo común es contar con verbos dicendi (67), construcciones impersonales en tercera persona del plural (68) y expresiones con pronombres genéricos como según esto (69):

67. Según se rumora si no refinamos gasolina aquí/ ¿qué podemos hacer? (CSCM México, 2011)

68. E: qué mala/ qué mala suerte le tocó a este de la Madrid/ ¿no?

I: pues sí/ con esas dos desgracias/ pero bueno ahí se vio/ según dicen/ ¿no?/ la solidaridad del pueblo// ¿no?/ ¡todos! tratando de cooperar (CSCM México, 2011)

69. y según esto/ esta mujer/ ya ves que es delegada ahí en Cuauhtémoc// según ella/ sus planes son// quitar el/ el/ el campo (CSCM México, 2011)

Lo que se observa es que la falta de definición de la fuente informativa genera la pérdida de confiabilidad de lo dicho. Como lo muestra la Figura 7, con fuentes difusas (el círculo punteado), la lectura deja de ser fidedigna; justo lo contrario que sucede con fuentes precisas y acreditadas: 


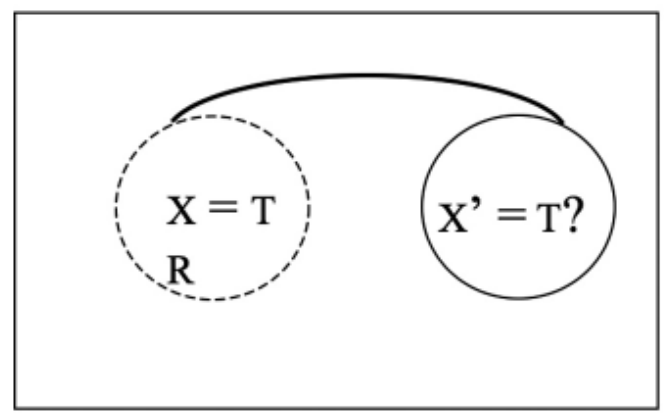

Figura 7. Baja confiabilidad (bearsay)

Obsérvese que el valor de según como creador de espacios mentales se preserva de manera esquemática. Pero la pérdida de rasgos semánticos se presenta de una construcción a otra. La progresión puede responder a la siguiente escala progresiva:

\section{Escala 2}

Proceder conforme al canon > citar contenidos a partir de documentos $>$ citar contenidos a partir de comunicadores acreditados $>$ citar contenidos a partir de fuentes difusas

La pérdida de validez evidencial se puede dar también bajo procesos restrictivos. Puesto que el español es una lengua de sujeto morfológico (pro-drop), el empleo de pronombres explícitos en la oración tiene funciones de focalización que tienden a responder a necesidades pragmáticas. Esto es justo lo que sucede. El uso de pronombres con según restringe el ámbito de la validez de una aseveración al dominio de tal pronombre, con lo cual, pierde su validez general. Los casos más claros ocurren en tercera persona del plural (70), aunque también es común en singular, con valor restrictivo, si la fuente informativa no es confiable (71):

70. vivía en un lugar quesque era muy/ muy bueno/ según ellos/ pero era la cosa más espantosa (CSCM México, 2011)

71. Salinas Pliego se ocupa en estos días de demandar a todo aquel que se atreva a criticarlo e incluso a informar sobre las actividades de su empresa, según él porque se trata de difamaciones. (CREA México, 1996) 
La veracidad de lo dicho no tiene relación con la realidad. Solo tiene validez en el universo referencial del pronombre (ellos, Salinas Pliego). De ahí que la colocación <según + pronombre> se emplee para cuestionar la veracidad de algo dicho. Si en tercera persona esto es constatable, lo es más en segunda o primera persona, porque la reducción del espacio de validación se centra en un espacio más restringido, el de los interlocutores:

72. le digo "bueno/ entonces/ ¿qué es un proyecto para ti?// o sea/ ¿cuáles son las necesidades que tú debieras apoyar según tú??" (CSCM México, 2011)

73. y le digo/ "bueno/ a ver/ según tú/ ¿cuánto vale tu libertad?/ ¿sabes esto cuánto...?/ (CSCM México, 2011)

Bien se puede ver que la restricción licencia significados de imprecación y de cuestionamiento. En (72) y (73) el hablante no solo restringe sino que cuestiona la mirada del oyente. La Figura 8 representa los usos restrictivos de la colocación <según + pronombre>. La falta de conexión con R pone en tela de juicio la veracidad de lo dicho y el pronombre restringe la validez de la afirmación al ámbito de un participante e impide que sea aceptado como verdad general:

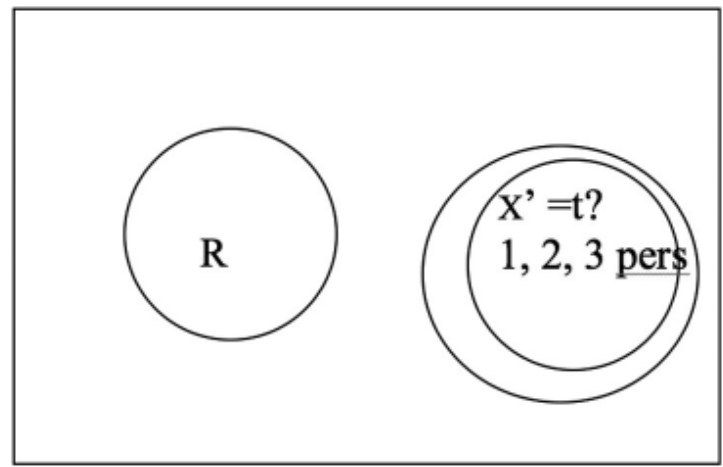

Figura 8. Validez restringida

La restricción de primera persona es todavía más interesante. Mientras que en segunda persona lo dicho es válido solo para el oyente, en la primera persona la restricción tiene más de una función. Además de la restrictiva, cumple con una función metalingüística de atenuación. De manera que las cosas no son 
verdad solo para mí, sino que se extiende su uso a propósitos de modulación. Tanto en (74) como en (75), el hablante atenúa y le quita peso a su aseveración por medio de según yo:

74. Entonces / lo que tienen que hacer/ según yo/ es ponerlo a/ a repartir cosas (CSCM México, 2011)

75. Aquel comentario, según yo, no podía ser otra cosa sino una franca provocación (CREA México, 1994)

Una atenuación mayor que se extiende a partir de los usos restrictivos es aquella en que según tú o según yo tienen la función epistémica de cuestionar radicalmente la veracidad de un hecho. Aquí los eventos declarados son meras simulaciones que nada tienen que ver con la realidad:

76. I: [porque haz de cuenta] que según tú estás lavando a/ a los muertitos

E: si uno se [baña] (CSCM México, 2011)

77. y me ponía a leer/ según yo me ponía a leer/ ¡y empezaba!/ a deletrear < deletríar> así/ este/ de una en otra letra (CSCM México, 2011)

En ambos casos se trata de actos imaginarios. El sujeto de (76) simula lavar a los muertos al bañarse, de la misma manera, el de (77) no sabe leer y solo finge hacerlo. Por supuesto que estos actos son reales en el ámbito ya sea del oyente o del hablante, pero al reducirse a espacios específicos, dejan de estar ligados al espacio R y pierden la posibilidad de ser aceptados como reales. En este uso, según se cruza con la lectura de dizque de apariencia o engaño (dizque trabaja de noche, dizque éramos amigos), donde la idea de aparentar se puede extender incluso a juegos imaginarios (dizque éramos bomberos, dizque llegabas volando) (De la Mora y Maldonado) que se pueden extender hasta la miratividad (Miglio). $\mathrm{Al}$ igual que dizque, según parte de un valor evidencial para convertirse en un marcador epistémico de cuestionamiento de verdad.

Los cambios de significado que hemos visto hasta este punto pueden ser vistos como el resultado de un complejo proceso de atenuación en que la pérdida de rasgos semánticos involucra una mayor participación del conceptualizador. En virtud de que según pierde progresivamente rasgos semánticos tiene cada vez menos restricciones. En un principio, seguía y reproducía modos de 
comportamiento plenamente establecidos; después, solo tomaba documentos escritos como fuentes confiables. De ahí empezó a aceptar fuentes calificadas y bien definidas que garantizaran la confiabilidad de la información. Después aceptó también fuentes difusas que reducían la confiabilidad de lo dicho. La pérdida del valor de verdad emerge con usos restrictivos en que el ámbito de veracidad se reduce a un participante, el hablante o el oyente, quienes, como tales, no garantizan veracidad alguna. Finalmente aparecen los usos metalingüísticos en que atenúan la fuerza ilocutiva del hablante.

En este largo proceso de atenuaciones, el último paso es la pérdida de restricciones selectivas. De conector oracional, según reduce su alcance no solo en frases verbales, sino también en frases nominales. Su función ahora no solo consiste en poner en tela de juicio la veracidad de una aseveración, sino que llega a cuestionar las propiedades de un sustantivo o de un atributo:

78. bueno/ el señor/ según era mi papá (CSCM México, 2011)

79. I: ...te vendan cosas piratas y la delegación te de un permiso/ para que vendas esas cosas piratas... o sea ¿cómo te explicas eso? no y es que según están combatiendo eso (CSCM México, 2011)

En (78), con alcance sobre el predicado nominal, el hablante es presentado como un señor a quien le querían hacer pasar por su padre. En (79), con alcance sobre la frase verbal, se cuestiona que las autoridades combatan el contrabando, cuando permiten la venta de mercancía ilegal. El cuestionamiento proviene de que según no tiene una fuente identificable en $\mathrm{R}$ que sustente la veracidad de lo afirmado. En esto, según parece estar siguiendo los pasos de dizque que, como marcador epistémico con alcance restringido sobre sustantivos, adjetivos y adverbios, cuestiona que el elemento modificado tenga todas las propiedades para ser considerado miembro legal de su categoría (mi dizque oficina, un señor dizque gentil, salió dizque rápido).

El conjunto de extensiones semánticas aquí visto sugiere una evolución en términos de atenuación, en que la mirada subjetiva del conceptualizador suple incrementalmente la pérdida de rasgos semánticos de la forma de base. La siguiente escala resume su evolución hacia usos cada vez más subjetivos:

Escala 3

Seguimiento de un patrón inicial $>$ determinación causal del patrón inicial $>$ reporte a partir de fuente documental (evidencial confiable) $>$ re- 
porte de una fuente oral definida (evidencial confiable) $>$ dispersión de la fuente informativa (evidencial no confiable) > restricción del ámbito de la predicación a un participante (epistémico cuestionable) > ausencia de la fuente informativa (epistémico no veraz)

En forma más esquemática tenemos una evolución conceptual que, con base en un espacio fuente (R), según se encarga de generar un nuevo espacio con los siguientes valores:

\section{Escala 4}

Seguimiento/determinación de un patrón $>$ evidencial confiable $>$ evidencial no confiable $>$ epistémico restrictivo $>$ epistémico no veraz

La amable pregunta de Elizabeth Traugott ${ }^{1}$ respecto de si esta evolución conceptual tenía alguna realidad histórica fue respondida positivamente, si bien con modificaciones respecto de la emergencia de los usos restrictivos, en otro estudio (Maldonado y De la Mora). Pero la dirección del cambio está corroborada. Mientras más rasgos se pierden, mayor es la participación subjetiva del conceptualizador en la conformación del sentido pragmático. Ello no implica que no haya cálculo inferencial. Según preserva su estructura esquemática fundamental como constructor de un espacio mental en liga con una fuente. Las propiedades referenciales de la fuente van disminuyendo hasta su total desaparición y, en esa disminución, operan inferencias claramente definibles. Una fuente definida y precisa es más confiable que una dispersa y sin validación. Las lecturas epistémicas se desprenden de que la fuente sea cada vez menos confiable.

\section{CONCLUSIONES}

En este trabajo he intentado sugerir que el análisis semántico es fundamental en el estudio de los sentidos pragmáticos de los marcadores discursivos. He seguido la propuesta de Langacker $(1985,1990)$, según la cual en la emergencia de los sentidos de corte pragmático interviene un proceso de atenuación semántica que implica una importante ruta de subjetivización: el hablante

1. Conceptual Structure, Discourse and Language. Conference. University of California, Santa Barbara, 2014. 
suple incrementalmente la pérdida de distintos rasgos semánticos de la forma de base. He ilustrado el fenómeno con dos casos que parten de puntos radicalmente distintos (claro y según) y que confluyen en la zona evidencial sin perder cada uno su perfil. Los pasos que involucra el proceso de pragmaticalización de cada forma están acotados por su esquema conceptual de base. En el adjetivo claro la noción de "acceso libre de obstáculos a un objeto mental" se preserva también en sus versiones más desemantizadas como marcador dialógico. Incluso sus sobretonos intencionales como marcador (acuerdo, reclamo, corrección, toma de turno, etc.) tienen como base el presupuesto de que la información está compartida indudablemente por hablante y oyente. $\mathrm{Y}$, por supuesto, en los usos construccionales menos atenuados, la presencia de la información fácilmente accesible es aún más notable. En todos los casos, las inferencias se activan en virtud de que la información se asume como evidente. Por su parte, según, como elemento relacional preserva su significado esquemático de "seguir el contenido de una fuente" a la que se accede anafóricamente. Ese seguimiento inicialmente fiel va dejando de serlo en virtud de que la fuente informativa pierde confiabilidad, ya porque pierda precisión, ya porque sea demasiado restrictiva. Los usos evidenciales de uno y otro marcador difieren justamente en lo que cada forma léxica perfila: facilidad de acceso (claro) versus seguimiento de un patrón (según). Para uno, el contenido del núcleo al que modifica es determinante; para el otro, dado su perfil relacional, la entidad de donde provenga la información es fundamental. En ese sentido, se puede afirmar que según se apega con mayor claridad a lo evidencial propiamente dicho. Todo parece indicar que lo semántico no solo alimenta lo inferencial en la construcción del contenido pragmático, sino que lo conforma y le da sentido.

\section{CORPUS}

Martín Butragueño, Pedro, y Yolanda Lastra. Corpus Sociolingüístico de la Ciudad de México. México: El Colegio de México, 2011.

Real Academia Española. Corpus de referencia del español actual (CREA), 2011.

\section{OBRAS CITADAS}

Aikhenvald, Alexandra. Evidentiality. Oxford: Oxford UP. 2004. Alonso Almeida, Francisco, y Heather Adams. "Sentential Evidentials in 
English Medical Research Papers". Revista de Lingüistica y Lenguas Aplicadas 7 (2012): 9-21.

Athanasiadou, Angeliki. "Adjectives and Subjectification". Subjectification: Various Paths to Subjectivity. Eds. Costas Canakis y Bert Cornillie. Berlin: De Gruyter Mouton, 2006. 210-39.

Bolinger, Dwight. "Adjectives in English: Attribution and Predication". Lingua 18 (1967): 1-34.

Briz, Antonio. "Los conectores pragmáticos en la conversación coloquial (II): su papel metadiscursivo". Español Actual 59 (1993): 39-56.

Chafe, Wallace. "Evidentiality in English Conversation and Academic Writing”. Evidentiality: The Linguistic Coding of Epistemology. Hilsdale (N.J.): Ablex, 1986. 261-73.

Cornillie, Bert. "The Shift from Lexical to Subjective Readings in Spanish. Prometer 'promise' and Amenazar 'threaten'. A Corpus-BasedAccount". Pragmatics 14.1 (2004): 1-30.

Cornillie, Bert. "On the Grammaticalization and (Inter) subjectivity of Evidential (Semi-) auxiliaries in Spanish". Theoretical and Empirical Issues in Grammaticalization. Eds. Elene Seoane y María José López Couzo. Amsterdam/ Philadelphia: John Benjamins, 2008. 55-78.

De la Mora, Juliana, y Ricardo Maldonado. "Dizque: Epistemics Blurring Evidentials in Mexican Spanish". Fournal of Pragmatics 85 (2015): 16880.

Delbecque, Nicole. "Las cópulas ser y estar: Categorización frente a deixis". Revista Española de Lingüística Aplicada 1 (2000): 239-80.

Delbecque, Nicole, y Ricardo Maldonado. "Spanish ya: A Conceptual Pragmatic Anchor". Fournal of Pragmatics 43.1 (2011): 73-98.

Demonte, Violeta, y Olga Fernández-Soriano. "El 'que' citativo en español y otros elementos de la periferia oracional. Variación inter e intralingüística”. Autour de que. El Entorno de que. Frankfurt am Main: Peter Lang, 2013. 43-63.

Fauconnier, Gilles. Mental Spaces: Aspects of Meaning Construction in Natural Language. Cambridge: Cambridge UP, 1985.

Freites Barros, Francisco. "El marcador de discurso claro: funcionamiento pragmático, metadiscursivo y organizador de la estructura temática". Verba 33 (2006): 261-79.

González Vergara, Carlos. "Estrategias gramaticales de expresión de la evidencialidad en el español de Chile". Alpha (Osorno) 32 (2011): 149-65. 
Halliday, Michael. An Introduction to Functional Grammar. London: Edward Arnold, 1985.

Hopper, Paul, y Elizabeth Closs Traugott. Grammaticalization. Cambridge Textbooks in Linguistics. Cambridge: Cambridge University Press, 1993.

Hummel, Martin. "Polyfunctionality, Polysemy, and Rethorical Strategy: The Functional Semantic and Pragmatic Motivation of Discourse Functions". Grazer Linguistische Studien 79 (2013): 63-91.

Lakoff, George. Women, fire, and dangerous things. Chicago: University of Chicago Press, 1987.

Lakoff, George, y Mark Turner. More than cool reason: The power of poetic metaphor. Berkeley: University of California at Berkeley, 1989.

Langacker, Ronald. "Observations and Speculations on Subjetivity". Iconicity in Syntax. Ed. John Haiman. Amsterdam: John Benjamins Publishing Company, 1985. 109-50.

Langacker, Ronald. "Subjectification". Concept, Image and Symbol: The Cognitive Basis of Grammar. New York: De Gruyter Mouton, 1990. 315-42.

Maldonado, Ricardo. “Objective and Subjective Datives". Cognitive Linguistics (2002): 1-65.

Maldonado, Ricardo. "Claro: de objeto perceptible a refuerzo pragmático". Adjetivos en discurso: emociones, certezas, posibilidades y evidencias. Ed. María José Rodríguez Espineira. Santiago de Compostela: Universidade de Santiago de Compostela, 2010. 61-108.

Maldonado, Ricardo, y Juliana De la Mora. "Según: A Space Builder into Mirativity". eHumanista/IVITRA 8 (2015): 488-99.

Martín Zorraquino, María Antonia. "Gramática del discurso: Los llamados marcadores del discurso". Actas del Congreso de la Lengua Española. Sevilla: Instituto Cervantes, 1994. 709-20.

Martín Zorraquino, María Antonia, y José Portolés. "Los marcadores del discurso". Gramática descriptiva del español. Dirs. Ignacio Bosque y Violeta Demonte. Madrid: Espasa Calpe, 1999. 4051-5013.

Miglio, Viola. "Online Databases and Language Change: The Case of Spanish Dizque". Language and Computers 71.1 (2009): 7-28.

Moliner, María. Diccionario de uso del español. Madrid: Gredos, 1999.

Nuyts, Jan. "Epistemic Modal Adverbs and Adjectives and the Layered Representation of Conceptual and Linguistic Structure". Linguistics 31 (1993): 933-70. 
Nuyts, Jan. "Subjectivity as an Evidential Dimension in Epistemic Modal Expressions". Fournal of Pragmatics 33.3 (2001): 383-400.

Olbertz, Hella. "Dizque in Mexican Spanish: The Subjectification of Reportative Meaning". Rivista di Linguistica 19.1 (2007): 151-72.

Paradis, Carita. Degree Modifiers of Adjectives in Spoken British English. Lund Studies in English 92. Lund: Lund University Press, 1997.

Quirk, Randolph. A Comprehensive Grammar of the English Language. London: Longman, 1985.

Real Academia Española. Diccionario de la lengua española. 23ª ed. Madrid: Espasa Calpe, 2014.

Shindo, Mika. "From Visual Adjective to Modalized Intensifier: A CrossLinguistic Study of Grammaticalization". New Reflections on Grammaticalization 4 (2008): 16-19.

Traugott, Elizabeth. "Pragmatic Strengthening and Gramaticalization". Proceedings of the Fourteenth Annual Meeting of the Berkeley Linguistics Society. Eds. Axmaker Shelley, Annie Jaisser y Helen Singmaster. Berkeley: Berkeley Linguistics Society, 1988. 406-16.

Traugott, Elizabeth. "Subjectification in Grammaticalization". Subjectivity and Subjectivisation. Eds. Susan Wright y Dieter Stein. Cambridge: Cambridge UP, 1995. 31-54.

Traugott, Elizabeth. "The Role of the Development of Discourse Markers in a Theory of Grammaticalization". International Conference of Historical Linguistics 123 (1995b): 1-26.

Verhagen, Arie. "On Subjectivity and «long Distance Wh-Movement»". Subjectification: Various Paths to Subjectivity. Eds. Costas Canakis y Bert Cornillie. Berlin: De Gruyter Mouton, 2006. 323-46. 

Semántica léxica, neología y terminología 
